\title{
Clinicopathological Features and Prognostic Outcomes of Papillary Renal Cell Carcinoma
}

\author{
Xiaoyuan Qian' \\ Junlai Wan $^{2}$ \\ Can Qian ${ }^{3}$ \\ Jiaqiao Zhang' \\ 'Department of Urology, Tongji Hospital, \\ Tongji Medical College, Huazhong \\ University of Science and Technology \\ Wuhan, People's Republic of China; \\ ${ }^{2}$ Department of Orthopedics, Tongji \\ Hospital, Tongii Medical College, \\ Huazhong University of Science and \\ Technology, Wuhan, People's Republic of \\ China; ${ }^{3}$ Department of Traditional \\ Chinese Medicine and Rheumatology, \\ Southwest Hospital, Army Military \\ Medical University, Chongqing, People's \\ Republic of China
}

Correspondence: Jiaqiao Zhang Department of Urology, Tongji Hospital, Tongji Medical College, Huazhong University of Science and Technology, 1095 Jiefang Avenue, Wuhan, Hubei Province, People's Republic of China Email medzjq@I63.com
Purpose: Although papillary renal cell carcinoma (pRCC) is the second common renal malignant tumor, the current understanding of pRCC is poor. This study aims to explore the clinicopathological features and prognostic factors of pRCC.

Methods: From August 2007 and August 2017, 87 patients diagnosed with pRCC by postoperative pathology were enrolled. The clinicopathological features between type1 pRCC and type 2 pRCC were compared by Chi-square test, Fisher's exact test, or $t$-test. The Kaplan-Meier method was performed to estimate progression-free survival (PFS). Univariate and multivariate cox regression models were used to verify the prognostic factors. Results: Of the 87 cases, the median tumor diameter was $5.3 \mathrm{~cm}$. Twenty-nine patients were diagnosed with type $1 \mathrm{pRCC}$ and 58 patients with type $2 \mathrm{pRCC}$. According pathological stage, $59(67.8 \%)$ cases were in pT1 stage, $19(21.8 \%)$ in pT2 stage, and $9(10.4 \%)$ in pT3 stage. WHO/ISUP pathological grade revealed that $56(64.4 \%)$ patients were in grade I, $17(19.5 \%)$ in grade II, $7(8.05 \%)$ in grade III, and $7(8.05 \%)$ in grade IV. The median follow-up time was 57.0months, and the 1-, 3-year PFS was $95.4 \%$, and $80.8 \%$, respectively. For type 1 and type 2 pRCC, 3-years PFS was $93.0 \%$ and $74.9 \%$, respectively. Survival of type1 pRCC was better than that of type $2(P=0.027)$. Patients with late pT stage, lymph node metastasis, distant metastasis, high pathological grade, and large size exhibited worse survival. pTNM stage, pathological grade, and tumor types were potentially related to prognosis for PFS. However, an independent prognostic factor affecting PFS was not found in multivariate regression models. For patients with the pT1 stage, nephron-sparing surgery (NSS) and radical nephrectomy $(\mathrm{RN})$ did not affect the PFS, ignoring tumor types $(P=0.45)$.

Conclusion: Type $2 \mathrm{pRCC}$ is more than type $1 \mathrm{pRCC}$ and has an advanced TNM stage and a higher pathological grade. For patients with pRCC with the pT1 stage, the outcome of NSS is not inferior to that of $\mathrm{RN}$.

Keywords: papillary renal cell carcinoma, clinical features, pathological features, prognosis

\section{Introduction}

PRCC is the second most common subtype of renal cell carcinoma (RCC) following clear cell RCC, originating from renal tubular epithelial cells and having papillary or tubular-papillary structures, which accounts for $10-14 \%$ of RCC.,2 According to the arrangement of tumor cells and nuclear grade, pRCC was classified into type 1 and type 2 . The prognosis of type 1 pRCC was better than that of type $2 \mathrm{pRCC}$ and cytogeny and molecular biology studies have shown that it had an independent genetic phenotype. ${ }^{3,4}$ Some clinical and pathological characteristics, including tumor Fuhrman's stage, tumor size, pathological grade, multifocality, and necrosis were considered to be related to outcomes of pRCCs. ${ }^{5,6}$ Tumor growth was 
slow and most patients were found in the early stage, thus pRCC showed a better prognosis. Although the prognosis of pRCCs was better than that of clear cell RCC, studies about the clinicopathological features and prognosis of pRCC were few for its low morbidity and fatality. And there is still no standard treatment strategy for pRCC. To have a good clinical understanding of these tumor characteristics, we therefore retrospectively analyzed the clinicopathologic features, treatment methods, and prognosis outcome of 87 patients with pRCC, who had undergone surgical treatment from August 2007 and August 2017. And for all we know, this study included the relatively large number of cases at a single institution for discussion and may provide a reference for clinical diagnosis and treatment of pRCC patients.

\section{Materials and Methods}

\section{Methods}

According to the Declaration of Helsinki, the Ethics Committee of Tongji Hospital, Tongji Medical College, Huazhong University of Science and Technology approved this study. Because this study belonged to a retrospective study, patient consent to review their medical records was waived. A total of 2240 patients were diagnosed with RCC and treated at Tongji Hospital, Tongji Medical College, Huazhong University of Science and Technology from August 2007 and August 2017. After the cases with incomplete clinicopathological data and lost follow-up were excluded, among RCC patients, 87 cases diagnosed with pRCC by pathology were eventually enrolled in the study. The median age of patients included was 53 years (IQR: 44 to 61years). All patients consisted of 21 (24.1\%) females and $66(75.9 \%)$ males. In terms of main clinical presentation, $50(57.5 \%)$ cases do not show significant symptoms, $22(25.3 \%)$ had hematuria and lower back pain, $9(10.3 \%)$ only presented hematuria, and $6(6.9 \%)$ other such as feeble, fever or discomfort in the waist. Among them, 33 (37.9\%) cases underwent NSS, and 54 (62.1\%) patients received $\mathrm{RN}$.

\section{Follow-Up}

Clinical data and abdominal CT follow-up information for patients with pRCC were mainly collected through outpatient data and added by a telephone interview. When disease recurrence was defined as local recurrence in the operative site, regional lymph nodes, or distant metastasis, RFS was defined as the time from the date of surgical therapy to the date of tumor recurrence or death caused by pRCC. All cases were followed up for a median of 57.0months (IQR: 43.5 to 72.0 months). The endpoint time of follow-up was viewed as the time of the death or up to May 1, 2020, for surviving patients.

\section{Statistical Analysis}

All statistical analyses were performed using R 3.6.3 software (The R Foundation for Statistical Computing, Vienna, Austria). Continuous data that belong to a normal distribution were presented as mean \pm standard deviation (SD) and performed with Student's $t$-test, while clinicopathologic characteristics with a non-normal distribution were described by the median and interquartile range (IQR) and compared by Mann-Whitney $U$-test. And categorical variables were recorded in numbers and percentages and were compared by Chi-square test or Fisher's exact test. Kaplan-Meier method was used to evaluated PFS and conducted survival curves. And Log rank tests were applied to compare differences between survival curves. The Cox proportional hazards regression model was used to analyze the factors affecting PFS. A $\mathrm{P}<0.05$ (two-sided) was considered to be statistically significant.

\section{Results}

\section{Description of Pathological Features}

In 87 cases, the mean maximum diameter of the tumor was $5.30 \mathrm{~cm}$ (IQR:3.65 to $7.15 \mathrm{~cm}$ ). The average age of type 2 pRCC was younger than that of type 1 pRCC $(P=0.024)$. According pathological stage, $59(67.8 \%)$ cases were in pT1 stage, $19(21.8 \%)$ in pT2 stage, $9(10.3 \%)$ in pT3 stage, and $0(0 \%)$ in pT4 stage. And WHO/ISUP pathological classification showed that $56(64.4 \%)$ patients were in grade I, 17 (19.5\%) in grade II, 7 (8.1\%) in grade III, and $7(8.1 \%)$ in grade IV. There were $19(21.8 \%)$ cases with necrosis in tumor tissues. After the operation, there were $29(33.3 \%)$ cases pathologically identified as type1 pRCC and 58 (66.7\%) type1 pRCC. Compared type1 pRCC, type 2 pRCC had an advanced T stage $(P=0.008)$, more positive node metastasis $(P=0.027)$, large tumor size $(P=0.005)$, and high pathological grade $(P=0.004)$. Differences between the two types of pRCC were summarized in Table 1.

All 87 patients underwent successful surgery. The median follow-up of this cohort was 57.0 months (IQR: 43.5 to 72.0 months). Of 87 patients, 10 (11.5\%) occurred 
Table I Comparison of Clinicopathological Features Between Type I and Type 2 pRCC

\begin{tabular}{|c|c|c|c|c|}
\hline Clinicopathologic Features & All (87) & Type I pRCC (29) & Type 2 pRCC (58) & $P$ value \\
\hline Sex, n (\%) & & & & 0.425 \\
\hline Female & $21(24.1 \%)$ & 5 (I7.2\%) & $16(27.6 \%)$ & \\
\hline Male & $66(75.9 \%)$ & $24(82.8 \%)$ & $42(72.4 \%)$ & \\
\hline Age, mean (SD) & $51.8(14.5)$ & $56.3(I I .7)$ & $49.5(15.3)$ & 0.024 \\
\hline BMI, median (QI, Q3) & $23.0(21.3,25.3)$ & $22.9(21.1,25.3)$ & $23.2(21.7,25.9)$ & 0.106 \\
\hline Smoking, n (\%) & & & & 0.304 \\
\hline Yes & $31(35.6 \%)$ & $13(44.8 \%)$ & $18(31.0 \%)$ & \\
\hline No & $56(64.4 \%)$ & $16(55.2 \%)$ & $40(69.0 \%)$ & \\
\hline Diabetes mellitus, n (\%) & & & & 1 \\
\hline Yes & $6(6.9 \%)$ & $2(6.9 \%)$ & $4(6.9 \%)$ & \\
\hline No & $81(93.1 \%)$ & 27 (93.1\%) & $54(93.1 \%)$ & \\
\hline Hypertension, n (\%) & & & & 0.425 \\
\hline Yes & $21(24.1 \%)$ & $9(31.0 \%)$ & $12(20.7 \%)$ & \\
\hline No & $66(75.9 \%)$ & $20(69.0 \%)$ & $46(79.3 \%)$ & \\
\hline Symptoms, n (\%) & & & & 0.088 \\
\hline Asymptom & $50(57.5 \%)$ & $18(62.1 \%)$ & 32 (55.2\%) & \\
\hline Hematuresis & $9(10.3 \%)$ & $0(0.0 \%)$ & 9 (I5.5\%) & \\
\hline Hematuresis and pain & $22(25.3 \%)$ & $8(27.6 \%)$ & $14(24.1 \%)$ & \\
\hline Other & $6(6.9 \%)$ & $3(10.3 \%)$ & $3(5.2 \%)$ & \\
\hline Laterality, n (\%) & & & & 0.255 \\
\hline Left & $45(51.7 \%)$ & $12(41.4 \%)$ & $33(56.9 \%)$ & \\
\hline Right & $42(48.3 \%)$ & $17(58.6 \%)$ & $25(43.1 \%)$ & \\
\hline Tumor size, median (QI, Q3) & $5.3(3.7,7.2)$ & $4.00(3.0,5.9)$ & $6.05(4.6,8.0)$ & 0.005 \\
\hline $\mathrm{T}, \mathrm{n}(\%)$ & & & & 0.008 \\
\hline TI & $59(67.8 \%)$ & $26(89.7 \%)$ & $33(56.9 \%)$ & \\
\hline $\mathrm{T} 2$ & $19(21.8 \%)$ & $2(6.90 \%)$ & 17 (29.3\%) & \\
\hline T3 & $9(10.4 \%)$ & I (3.4\%) & $8(13.8 \%)$ & \\
\hline $\mathrm{N}, \mathrm{n}(\%)$ & & & & 0.027 \\
\hline No & 77 (88.5\%) & $29(100 \%)$ & $48(82.8 \%)$ & \\
\hline $\mathrm{NI}$ & $10(11.5 \%)$ & $0(0.0 \%)$ & $10(17.2 \%)$ & \\
\hline$M, n(\%)$ & & & & 0.172 \\
\hline MO & 81 (93.1\%) & $29(100 \%)$ & 52 (89.7\%) & \\
\hline MI & $6(6.9 \%)$ & $0(0.0 \%)$ & $6(10.3 \%)$ & \\
\hline Pathological grading, n (\%) & & & & 0.004 \\
\hline I & $56(64.4 \%)$ & $26(89.7 \%)$ & $30(51.7 \%)$ & \\
\hline II & $17(19.5 \%)$ & $2(6.9 \%)$ & $15(25.9 \%)$ & \\
\hline III & 7 (8.1\%) & I (3.5\%) & $6(10.3 \%)$ & \\
\hline IV & $7(8.1 \%)$ & $0(0.0 \%)$ & $7(12.1 \%)$ & \\
\hline ASA, n (\%) & & & & 0.439 \\
\hline I & II (I2.6) & $3(10.3 \%)$ & 8 (I3.8\%) & \\
\hline 2 & 65 (74.7\%) & 21 (72.4\%) & 44 (75.9\%) & \\
\hline 3 & 9 (10.3\%) & 5 (I7.2\%) & $4(6.9 \%)$ & \\
\hline 4 & $2(2.3 \%)$ & $0(0.0 \%)$ & $2(3.5 \%)$ & \\
\hline
\end{tabular}


Table I (Continued).

\begin{tabular}{|l|l|l|l|l|}
\hline Clinicopathologic Features & All (87) & Type I pRCC (29) & Type 2 pRCC (58) & P value \\
\hline Resection mode, n (\%) & & & & \\
NSS & $33(37.9 \%)$ & $13(44.8 \%)$ & $20(34.5 \%)$ \\
RN & $54(62.1 \%)$ & $16(55.2 \%)$ & $38(65.5 \%)$ & \\
\hline Necrosis, n (\%) & & & $12(20.7 \%)$ \\
Yes & $19(21.8 \%)$ & $7(24.1 \%)$ & $46(79.3 \%)$ \\
No & $68(78.2 \%)$ & $22(75.9 \%)$ & 0.927 \\
\hline
\end{tabular}

Abbreviations: BMI, body mass index; NSS, the nephron-sparing surgery; RN, radical nephrectomy; ASA, American Society of Anesthesiologists.

lymph node metastasis, and $6(6.9 \%)$ had distant metastasis (including 3 lung metastases, 1 bone metastases, 1 liver metastases, and retroperitoneal metastasis, and 1 psoas major metastasis). During the follow-up period, 19 patients developed progression of the disease and 9 patients died from all causes. PFS was obtained by the Kaplan-Meier method and the 1-, 3- and 5-year PFS of 87 patients were $95.3 \%, 83.0 \%, 83.0 \%$, respectively. There was a better PFS in patients with the pT3 stage than that in patients with pT1/pT2 $(P<0.001$, Figure 1A). And lymph node metastasis made patients with $\mathrm{pRCC}$ worse PFS $(P<0.001$, Figure 1B). Similarly, the distant metastasis of the tumor could shorten the PFS of pRCC patients $(P<0.001$, Figure 1C). And an advanced pathological grade was also not conducive to PFS $(P<0.001$, Figure 1D). The patients with type 2 pRCC exhibited better PFS $(P=0.027$, Figure 1E) than patients with type $1 \mathrm{pRCC}$. In addition, small tumor size patients presented higher PFS than large tumor size patients $(P=0.047$, Figure $1 \mathrm{~F})$.
A

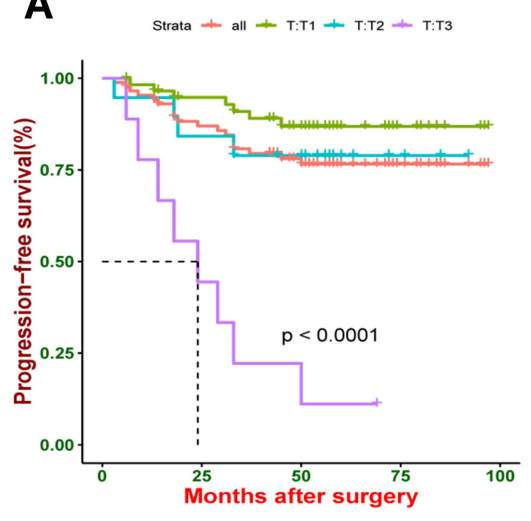

D

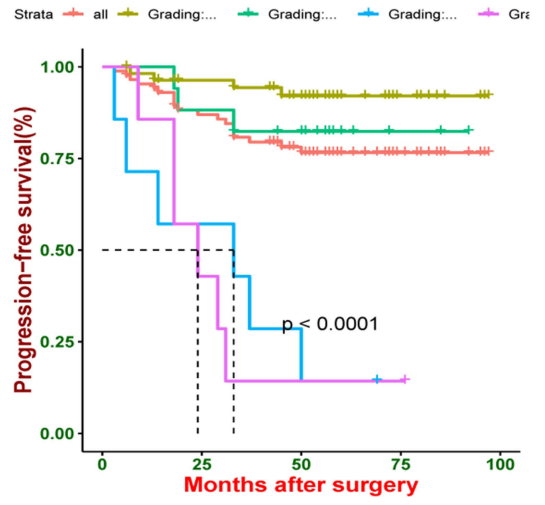

B

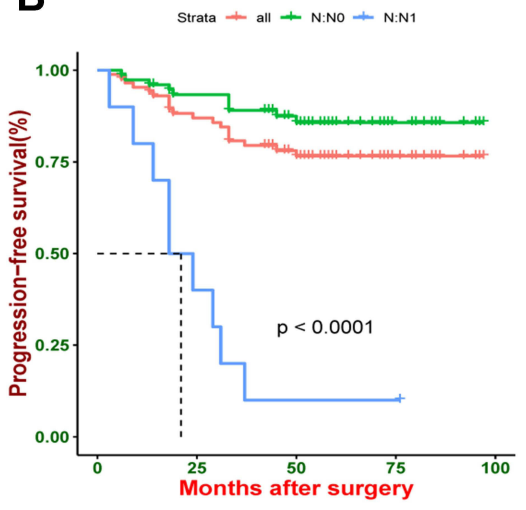

E

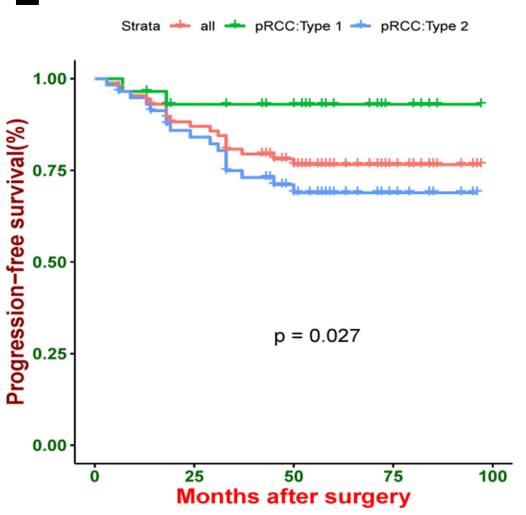

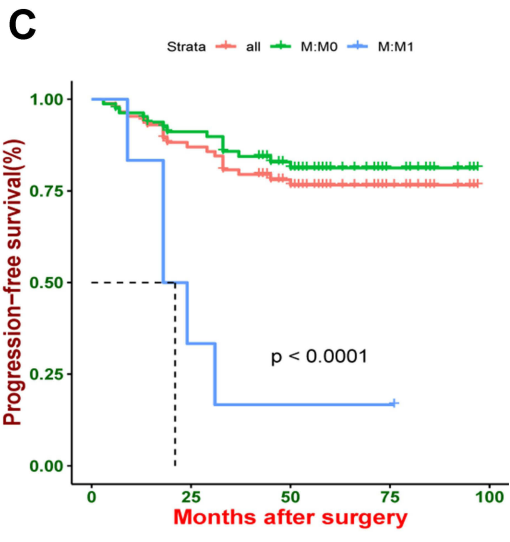

$\mathbf{F}$

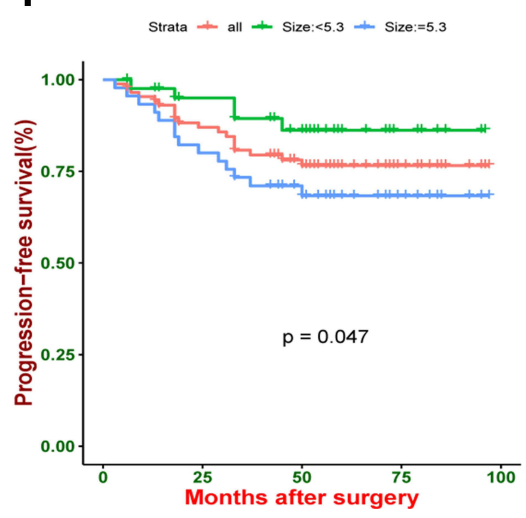

Figure I Kaplan-Meier estimate of progression-free survival by (A) T classification, (B) N classification, (C) M classification, (D) pathological grading, (E) histopathologic type, and (F) tumor size. 

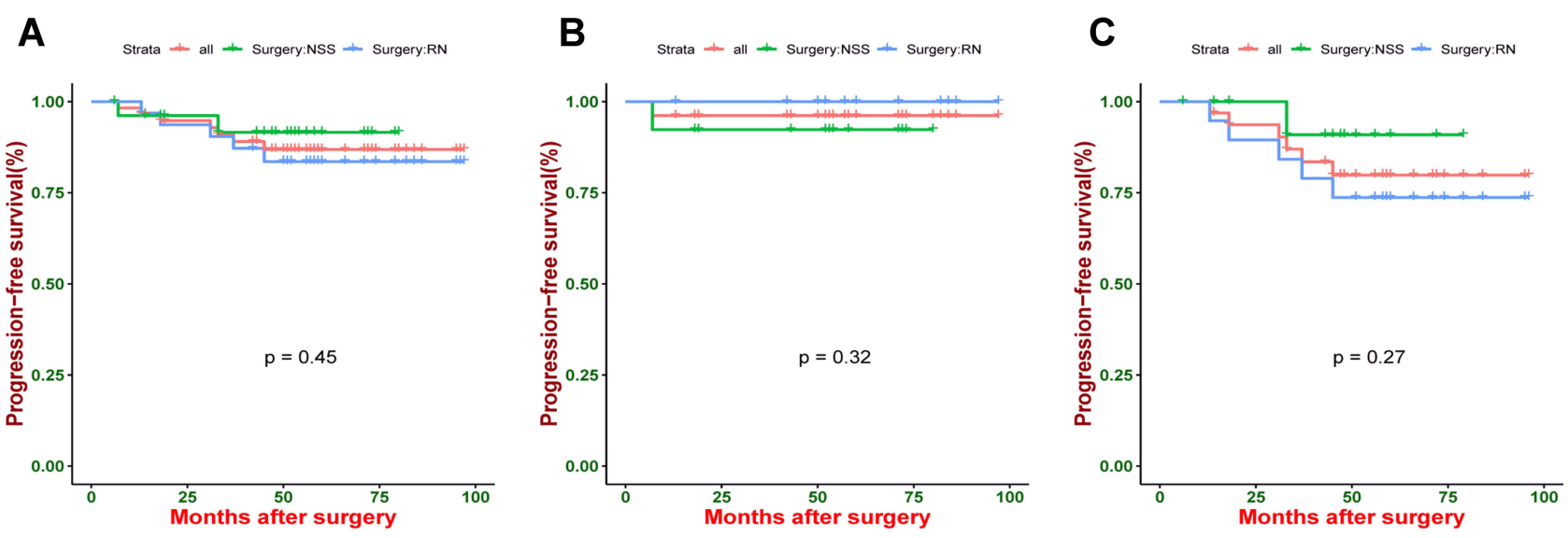

Figure 2 Kaplan-Meier survival curves of progression-free survival for procedure type. (A) all patients in PTI stage, (B) typel pRCC patients in pTI stage, and (C) type2 PRCC patients in PTI stage.

Stratified analysis was performed according to the pT stage, NSS or RN had nothing to do with PFS in patients with pRCC at the pT1 stage (Figure 2A). Similarly, we grouped $\mathrm{T} 1$ patients by tumor type and discovered that patients' PFS were not affected by the method of surgery (Figure 2B and C).

\section{Univariate and Multivariate Analysis of Prognostic Factors for PFS}

The median PFS was 53.0 months (IQR: 33.0 to 71 months). The results of univariate analysis of factors that affected the prognosis of the tumor were shown in Table 2. In the univariable Cox regression models, TNM classification, pathological grade, and tumor histopathologic type were significantly associated with PFS $(P<0.05)$. All factors with $P<0.1$ in univariable Cox regression model analysis were then included and adjusted by multivariable Cox regression model analysis (Table 2). However, some factors affecting PFS in patients with pRCC were not found (Table 2).

\section{Discussion}

PRCC is the second subtype of RCC, but overall incidence is relatively low, and relevant studies about its clinicopathological characteristics and outcomes of pRCC are not well researched and need to be improved. Compared with clear cell RCC, most patients were recognized early, and only a small number of patients had nodal or distant metastases occurring. ${ }^{7}$ PRCC was pathologically divided into two subtypes - type 1 and type2. ${ }^{8,9}$ There also existed differences in clinicopathologic features and prognosis between the two types. And pRCC typel was more common and less malignant than type 2 pRCC, which were generally considered to present a better prognosis than pRCC type $2 .{ }^{10-12}$ To deepen clinicians' understanding of this tumor and guide clinical decision-making, we summarized the clinicopathologic features of pRCC and analyzed its prognostic characteristics. And what we found was that the clinicopathological features did differ significantly between the two types of tumor and type 2 pRCC had an advanced TNM stage and a higher pathological grade and that regardless of the type of tumor, patients benefited from the early operation.

PRCC had a different low incidence of kidney tumors. It accounted for $5 \%$ of RCC in Korea. ${ }^{13}$ Similarly, the incidence of pRCC also was reported by Japanese scholars $^{14}$ and in the United States, that was $9.7 \%$ of RCC. ${ }^{15}$ And in some European countries, such as Germany, there was more than $10 \%$ incidence reported. ${ }^{2}$ In our cohort, pRCC accounted for 3.9\% (87/2240) of RCC, which was lower than that occurred in the United States or European countries, similar to what has been reported in Asian countries-Japan, South Korea, and China. And that Asian population had a low incidence of pRCC was shown. In addition, different from the results of previous studies, type $1 \mathrm{pRCC}$ was not common. The number of type 2 pRCC was about twice as large as type 1 pRCC in our department. The cause of these differences may be that the population enrolled in this study was all from Chinese areas, which may result in population differences and geographical differences.

Most patients with pRCC often lack typical clinical manifestations and are incidentally detected during physical examination. In this study, $57.5 \%$ of the patients found by physical examination did not present discomfort, and 
Table 2 Univariable and Multivariable Cox Regression Model Analysis of PFS for pRCC Patients

\begin{tabular}{|c|c|c|c|c|}
\hline \multirow[t]{3}{*}{ Variables } & \multicolumn{2}{|l|}{ Univariable Cox } & \multicolumn{2}{|l|}{ Multivariable Cox } \\
\hline & \multicolumn{2}{|c|}{ Progression-Free Survival } & \multicolumn{2}{|c|}{ Progression-Free Survival } \\
\hline & HR (95\% Cl) & $P$-value & HR (95\% Cl) & $P$-value \\
\hline Sex & & & & \\
\hline Female & Reference & & & \\
\hline Male & $0.66[0.20 ; 2.19]$ & 0.497 & & \\
\hline Age (years) & & & & \\
\hline$<40$ & Reference & & & \\
\hline $40-60$ & $1.015[0.27 ; 3.83]$ & 0.441 & & \\
\hline$\geq 60$ & $1.69[0.45 ; 6.36]$ & 0.983 & & \\
\hline Smoking & & & & \\
\hline No & Reference & & & \\
\hline Yes & $0.40[0.13 ; 1.21]$ & 0.105 & & \\
\hline Hypertension & & & & \\
\hline No & Reference & & & \\
\hline Yes & $0.32[0.07 ; 1.37]$ & 0.123 & & \\
\hline Diabetes & & & & \\
\hline No & Reference & & & \\
\hline Yes & $1.68[0.39 ; 7.26]$ & 0.491 & & \\
\hline Laterality & & & & \\
\hline Left & Reference & & & \\
\hline Right & $0.66[0.26 ; 1.64]$ & 0.368 & & \\
\hline Tumor size $(\mathrm{cm})$ & & & & \\
\hline$<5.3 \mathrm{~cm}$ & Reference & & Reference & \\
\hline$\geq 5.3 \mathrm{~cm}$ & $2.69[0.97 ; 7.46]$ & 0.058 & $0.73[0.18 ; 2.90]$ & 0.656 \\
\hline T stage & & & & \\
\hline TI & Reference & & Reference & \\
\hline $\mathrm{T} 2$ & $1.78[0.52 ; 6.07]$ & 0.359 & $\mathrm{I} .45[0.32 ; 6.61]$ & 0.53 \\
\hline T3 & $7.58[1.89 ; 30.36]$ & 0.003 & $2.82[0.59 ; 13.57]$ & 0.331 \\
\hline $\mathrm{N}$ stage & & & & \\
\hline No & Reference & & Reference & \\
\hline $\mathrm{NI}$ & $|4.3|[5.57 ; 36.76]$ & 0.001 & $3.61[0.59 ; 22.21]$ & 0.165 \\
\hline M stage & & & & \\
\hline Mo & Reference & & Reference & \\
\hline MI & $8.56[2.98 ; 24.59]$ & 0.044 & $0.72[0.17 ; 2.99]$ & 0.654 \\
\hline Pathological grading & & & & \\
\hline 1 & Reference & & & \\
\hline II & $2.4 I[0.54 ; 10.77]$ & 0.249 & $1.23[0.004 ; 35.05]$ & 0.946 \\
\hline III & $10.52[5.33 ; 67.53]$ & 0.014 & $\mathrm{I} .50[0.06 ; 40.33]$ & 0.808 \\
\hline IV & $22.89[6.23 ; 84.15]$ & 0.006 & - & 0.998 \\
\hline Resection mode & & & & \\
\hline NSS & Reference & & & \\
\hline $\mathrm{RN}$ & $1.59[0.57 ; 4.43]$ & 0.371 & & \\
\hline
\end{tabular}

(Continued) 
Table 2 (Continued).

\begin{tabular}{|c|c|c|c|c|}
\hline \multirow[t]{3}{*}{ Variables } & \multicolumn{2}{|l|}{ Univariable Cox } & \multicolumn{2}{|c|}{ Multivariable Cox } \\
\hline & \multicolumn{2}{|c|}{ Progression-Free Survival } & \multicolumn{2}{|c|}{ Progression-Free Survival } \\
\hline & HR (95\% Cl) & $P$-value & HR $(95 \% \mathrm{Cl})$ & $P$-value \\
\hline \multicolumn{5}{|l|}{$\mathrm{pRCC}$} \\
\hline Type I & Reference & & Reference & \\
\hline Type 2 & $4.51[1.04 ; 19.53]$ & 0.044 & $2.23[0.46 ; 10.89]$ & 0.32 \\
\hline \multicolumn{5}{|c|}{ Necrosis, n (\%) } \\
\hline No & Reference & & & \\
\hline Yes & I.76 [0.67; 4.62] & 0.255 & & \\
\hline
\end{tabular}

Abbreviations: $\mathrm{Cl} \%$, confidence interval; $\mathrm{HR}$, hazard ratio.

the remained patients presented clinical symptoms- hematuria $(10.3 \%)$, hematuria combined with waist pain $(25.3 \%)$, and other symptoms, such as feebleness, fever, etc. We also found that recurrence and metastasis tended to occur in patients with type 2 pRCC, which often caused hematuria, waist pain, or other symptoms.

In terms of features under the microscope, type 1 pRCC has lots of papillae and tubular structures which covered many small single-layer tumor cells with pale cytoplasm, small oval nuclei, frequent glomeruloid papillae, papillary edema, foamy macrophages in papillary cores, and psammoma bodies. Type 2 tumor cells mainly consist of papillary structures covered with pseudostratified cells and it has large cells with abundant eosinophilic cytoplasm, obvious nucleoli in the nucleus. ${ }^{8}$

In our cohort, $59(67.8 \%)$ cases were in pT1 stage, 19 $(21.8 \%)$ in pT2 stage, $9(10.3 \%)$ in pT3 stage, and $0(0 \%)$ in pT4 stage. And WHO/ISUP pathological classification showed that $56(64.4 \%)$ patients were in grade I, 17 $(19.5 \%)$ in grade II, $7(8.1 \%)$ in grade III, and $7(8.1 \%)$ in grade IV. Consistent with previous studies, ${ }^{13,16}$ most of the pathological stages of pRCC were early stage, mainly $\mathrm{T} 1$ stage, and the majority of pathological grades were grade I and grade II. Delahunt and collaborators reported that the classification of pRCC was an important prognostic factor. ${ }^{8}$ Type 2 pRCC had a higher pathological grade, a later tumor stage, and a worse prognosis. Therefore, the clinicopathological differences between type 1 and type 2 pRCC require further stratified analysis. In our results, patients with type 1 pRCC in pT1, and pT2 accounted for $96.6 \%$, and patients with pT3 and pT4 only for $3.4 \%$, while type 2 pRCC patients with pT1 and pT2 accounted for $86.2 \%$, and with pT3 for $13.8 \%(\mathrm{P}<0.05)$. In terms of pathological grading, the number of type $1 \mathrm{pRCC}$ in grades I and II (96.6\%) was more than type 2 pRCC in grades I and II (77.6\%). Type 2 pRCC had a late pT stage and a high pathological grade $(\mathrm{P}<0.05)$. The pathological characteristics of type 2 pRCC suggested that their tumor biological behavior was more aggressive.

In renal cell carcinoma, the prognosis of $\mathrm{pRCC}$ is better, and type 2 pRCC has a worse prognosis than type $1 .{ }^{17,18}$ In our study, the 3-year PFS of patients with type 1 and type 2 pRCC was $92.2 \%$ and $78.9 \%$, respectively, still indicating that type 2 pRCC had a worse prognosis than type 1 pRCC. At present, there are still different opinions about other factors related to the survival of $\mathrm{pRCC}$ patients. Pierre Bigot revealed that the tumor stage superior to $\mathrm{pT} 1$ was the only prognostic factor of $\mathrm{pRCC} .{ }^{10}$ Cornejo et al found that only ISUP nucleolar grade and lymphovascular invasion were independently prognostic for CSS and OS. ${ }^{16}$ But in Géraldine Pignot's study, tumor type and TNM stage were two major significant prognostic factors. ${ }^{3}$ And in our study, pTNM classification, pathological classification, and types of pRCC were potentially related to prognostic outcome, but no significant factor affecting the PFS of patients with pRCC was recognized. Besides histopathological features and molecular factors, Immunocore was focused on in recent studies and was applied to evaluate its impact on oncological outcomes of RCC. The combination of Immunocore and clinicopathological features - TNM stage, Fuhrman grade, or the WHO/ISUP 2016 grade - can better evaluate oncological outcomes of renal tumors. ${ }^{19}$ And the outcome and tumor immunology of non-ccRCC subtypes were not very same as ccRCC. ${ }^{20,21}$ Although the effect of Immunocore on predicting prognosis in non-ccRCC cases was not still observed, the role of Immunocore in estimating the prognosis of pRCC was worth being investigated in the following study. $^{21}$ And more large prospective, well-designed studies are needed to confirm these results. 
Different surgical methods have different impacts on the prognosis of cancer patients, which are often developed following the principle of minimal injury to the patient. Type 2 pRCC is more aggressive than type1, and its pathological stage and grade of the tumor are higher. And most scholars recommend radical surgery for patients with type 2 pRCC. However, the histological classification of pRCC had no significant effect on the prognosis of patients undergoing NSS. ${ }^{10}$ And the localized pRCC had a good prognosis following NSS. In our study, surgical methods (NSS and RN) also did not affect the postoperative PFS of patients with the pT1 stage $(P=0.45)$. The same result was also obtained when patients were divided into subgroups by histological type. Equally important, surgical methods were also not a risk factor affecting PFS in multivariate cox regression models. Therefore, if the conditions were met, NSS was a feasible option for patients with early localized pRCC.

This study belonged to retrospective analysis. When the tumor stages were the same, the surgeon may choose NSS or RN according to the tumor location and the general condition of the patient, which made the results biased. However, during the limited follow-up period of this study, the prognosis of pT1 patients with typel or type 2 pRCC who underwent NSS was not inferior to that of $\mathrm{RN}$. Therefore, the results may suggest that whatever type of pRCC at the pT1 stage, NSS can be considered.

\section{Conclusion}

In short, pRCC is a relatively rarely rare clinical renal cell carcinoma with a good prognosis. It is mainly diagnosed by pathological morphology and its clinical manifestations are similar to other types of RCC. Type2 pRCC was more malignant and aggressive than type1 pRCC. And although type $1 \mathrm{pRCC}$ was less common, it was generally considered to present a better prognosis than pRCC type2. The outcome of NSS is the same as that of RN and NSS may be considered.

\section{Abbreviations}

pRCC, papillary renal cell carcinoma; PFS, progressionfree survival; WHO/ISUP, World Health Organization/ International Society of Urological Pathology; TNM, Tumor Node Metastasis; IQR, interquartile range; NSS, nephron-sparing surgery; RN, radical nephrectomy; RCC, renal cell carcinoma.

\section{Data Sharing Statement}

The data supporting the findings of this study are available from the corresponding author upon reasonable request.

\section{Ethics Approval and Consent to Participate}

Because this study belonged to a retrospective study, patient consent to check their medical records was waived. And all patient information collection and processing were strictly confidential and our procedures were carried out according to the Declaration of Helsinki. And the Ethics Committee of Tongji Hospital, Tongji Medical College, Huazhong University of Science and Technology approved this study.

\section{Funding}

This work was financially supported by the National Natural Science Foundation of China. (No.8190034453).

\section{Disclosure}

The authors declare that they have no competing interests.

\section{References}

1. Keegan KA, Schupp CW, Chamie K, et al. Histopathology of surgically treated renal cell carcinoma: survival differences by subtype and stage. J Urol. 2012;188(2):391-397. doi:10.1016/j.juro.2012.04.006

2. Steffens S, Janssen M, Roos FC, et al. Incidence and long-term prognosis of papillary compared to clear cell renal cell carcinoma-a multicentre study. Eur $J$ Cancer. 2012;48(15):2347-2352. doi:10.1016/j.ejca.2012.05.002

3. Pignot G, Elie C, Conquy S, et al. Survival analysis of 130 patients with papillary renal cell carcinoma: prognostic utility of type 1 and type 2 subclassification. Urology. 2007;69(2):230-235. doi:10.1016/j. urology.2006.09.052

4. Akhtar M, Al-Bozom IA, Al Hussain T. Papillary Renal Cell Carcinoma (PRCC): an update. Adv Anat Pathol. 2019;26 (2):124-132. doi:10.1097/PAP.0000000000000220

5. Amin MB, Corless CL, Renshaw AA, et al. Papillary (chromophil) renal cell carcinoma: histomorphologic characteristics and evaluation of conventional pathologic prognostic parameters in 62 cases. Am J Surg Pathol. 1997;21(6):621-635. doi:10.1097/00000478-199706000-00001

6. Ljungberg B, Albiges L, Abu-Ghanem Y, et al. European Association of Urology guidelines on renal cell carcinoma: the 2019 update. Eur Urol. 2019;75(5):799-810. doi:10.1016/j.eururo.2019.02.011

7. Rosiello G, Palumbo C, Knipper S, et al. Comparison of survival outcomes in patients with metastatic papillary vs. clear-cell renal cell carcinoma: a propensity-score analysis. World J Urol. 2021;39 (2):461-472. doi:10.1007/s00345-020-03187-y

8. Delahunt B, Eble JN. Papillary renal cell carcinoma: a clinicopathologic and immunohistochemical study of 105 tumors. Mod Pathol. 1997;10(6):537-544.

9. Delahunt B, Eble JN, McCredie MR, et al. Morphologic typing of papillary renal cell carcinoma: comparison of growth kinetics and patient survival in 66 cases. Hum Pathol. 2001;32(6):590-595. doi:10.1053/hupa.2001.24984

10. Bigot P, Bernhard JC, Gill IS, et al. The subclassification of papillary renal cell carcinoma does not affect oncological outcomes after nephron sparing surgery. World J Urol. 2016;34(3):347-352. doi:10.1007/s00345-015-1634-0

11. Ledezma RA, Negron E, Paner GP, et al. Clinically localized type 1 and 2 papillary renal cell carcinomas have similar survival outcomes following surgery. World J Urol. 2016;34(5):687-693. doi:10.1007/ s00345-015-1692-3 
12. Moch H, Cubilla AL, Humphrey PA, et al. The 2016 WHO classification of tumours of the urinary system and male genital organs-part A: renal, penile, and testicular tumours. Eur Urol. 2016;70 (1):93-105. doi:10.1016/j.eururo.2016.02.029

13. Ha YS, Chung JW, Choi SH, et al. Clinical significance of subclassification of papillary renal cell carcinoma: comparison of clinicopathologic parameters and oncologic outcomes between papillary histologic Subtypes 1 and 2 using the Korean renal cell carcinoma database. Clin Genitourin Cancer. 2017;15(2):e181-e186. doi:10.1016/j.clgc.2016.07.020

14. Yamashita S, Ioritani N, Oikawa K, et al. Morphological subtyping of papillary renal cell carcinoma: clinicopathological characteristics and prognosis. Int J Urol. 2007;14(8):679-683. doi:10.1111/j.14422042.2007.01805.x

15. Patard JJ, Leray E, Rioux-Leclercq N, et al. Prognostic value of histologic subtypes in renal cell carcinoma: a multicenter experience. J Clin Oncol. 2005;23(12):2763-2771. doi:10.1200/JCO.2005.07.055

16. Cornejo KM, Dong F, Zhou AG, et al. Papillary renal cell carcinoma: correlation of tumor grade and histologic characteristics with clinical outcome. Hum Pathol. 2015;46(10):1411-1417. doi:10.1016/j. humpath.2015.07.001
17. $\mathrm{Ku} \mathrm{JH}$, Moon $\mathrm{KC}$, Kwak C, et al. Is there a role of the histologic subtypes of papillary renal cell carcinoma as a prognostic factor? Jpn J Clin Oncol. 2009;39(10):664-670. doi:10.1093/jjco/hyp075

18. Wong ECL, Di Lena R, Breau RH, et al. Morphologic subtyping as a prognostic predictor for survival in papillary renal cell carcinoma: type 1 vs. type 2. Urol Oncol. 2019;37(10):721-726. doi:10.1016/j. urolonc.2019.05.009

19. Selvi I, Demirci U, Bozdogan N, et al. The prognostic effect of immunoscore in patients with clear cell renal cell carcinoma: preliminary results. Int Urol Nephrol. 2020;52(1):21-34. doi:10.1007/ s11255-019-02285-0

20. Delahunt B, Eble JN, Egevad L, et al. Grading of renal cell carcinoma. Histopathology. 2019;74(1):4-17. doi:10.1111/his.13735

21. Selvi I, Demirci U, Bozdogan N, Basar H. Does immunoscore have a significant effect on survival for non-clear cell renal cell carcinoma as well as clear cell renal cell carcinoma? Int Urol Nephrol. 2021;53 (6):1135-1138. doi:10.1007/s11255-020-02766-7
International Journal of General Medicine

\section{Publish your work in this journal}

The International Journal of General Medicine is an international, peer-reviewed open-access journal that focuses on general and internal medicine, pathogenesis, epidemiology, diagnosis, monitoring and treatment protocols. The journal is characterized by the rapid reporting of reviews, original research and clinical studies
Dovepress

across all disease areas. The manuscript management system is completely online and includes a very quick and fair peer-review system, which is all easy to use. Visit http://www.dovepress.com/ testimonials.php to read real quotes from published authors. 